\title{
Effectiveness of carboxytherapy in the treatment of cellulite in healthy women: a pilot study
}

This article was published in the following Dove Press journal:

Clinical, Cosmetic and Investigational Dermatology

22 August 2016

Number of times this article has been viewed

\author{
Luana Ramalho Pianez' \\ Fernanda Silva Custódio' \\ Renata Michelini Guidi ${ }^{1-4}$ \\ Jauru Nunes de Freitas ${ }^{5-7}$ \\ Estela Sant'Ana ${ }^{8-10}$ \\ 'Ibramed Center for Education \\ and Advanced Training (CEFAI), \\ Amparo, ${ }^{2}$ Irmandade Santa Casa de \\ Misericórdia, São Paulo, ${ }^{3}$ University \\ of Campinas, Campinas, ${ }^{4} \mathrm{lbramed}$ \\ Research and Development \\ Department, Amparo, São Paulo, \\ Brazil; ${ }^{5}$ Universitá Tor Vergata, Rome, \\ Italy; ${ }^{6}$ Centro de Medicina Pesquisa \\ e Ensino (CEMEPE), Belo Horizonte, \\ ${ }^{7}$ Advanced Dermatology Studies \\ Group (GDA), Rio de Janeiro, ${ }^{8} \mathrm{Federal}$ \\ University of São Carlos (UFSCAR), \\ 'University of São Paulo (USP), \\ São Carlos, ${ }^{10}$ Indústria Brasileira de \\ Equipamentos Médicos (IBRAMED), \\ Amparo, São Paulo, Brazil
}

Correspondence: Estela Sant'Ana IBRAMED, Av Dr Carlos Burgos, 2800, Jd Itália, CEP I390I-080, Amparo, São Paulo, Brazil

Tel +55 I9 38179633

$\mathrm{Fax}+551938179634$

Email estela@ibramed.com.br
Background: Carbon dioxide therapy, better known as carboxytherapy, relates to percutaneous infusion of medical carbon dioxide with therapeutic approaches, and its use in the treatment of localized fat has demonstrated good results. Gynoid lipodystrophy, also known as cellulite, affects $80 \%-90 \%$ of women after puberty, especially in the buttocks and thighs. Its etiology is complex and involves multifactorial aspects. Its treatment and evaluation require the use of new technologies (more effective and low-cost approaches). The objective was to investigate the effectiveness of carboxytherapy in the treatment of cellulite in the areas of buttocks and posterior thigh.

Patients and methods: Ten women, $29 \pm 6.1$ years, were selected and all of them received eight treatment sessions, with an interval of 7 days between sessions. Standardized digital photographs were used to assess the severity of cellulite, and panoramic images were collected by ultrasound diagnosis. The evaluations were performed before the first treatment (baseline) and 7 days after the last treatment session of carboxytherapy.

Results: After the treatment, there was a significant reduction $(P=0.0025)$ of the cellulite from degree III to degree II, and this improvement had correlation with the improvement in the organization of the fibrous lines and the disposal of adipose tissue lines of the treated regions observed through the panoramic ultrasound images diagnosis.

Conclusion: Carboxytherapy is an effective technique of treatment of cellulite in the buttocks region and posterior thighs of healthy women.

Keywords: carbon dioxide, cellulite, localized fat, gynoid lipodystrophy, skin, panoramic ultrasound

\section{Introduction}

Cellulite refers to a change that gives the skin a wavy and irregular appearance, and it affects $80 \%-90 \%$ of women after puberty. Numerous treatments have been proposed such as balanced diet, physical activity, massage, topical products, radiofrequency, therapeutic ultrasound, and light emitting diode therapy, among others. ${ }^{1}$ Carbon dioxide $\left(\mathrm{CO}_{2}\right)$ therapy, commonly known as carboxytherapy, refers to the administration of $\mathrm{CO}_{2}$ with therapeutic proposals. The technique originated in France in 1932, and originally the treatment was carried out percutaneously (through the skin) by the so-called heated carbonated water baths or the application of water-saturated $\mathrm{CO}_{2}$ directly to the skin of patients. The technique was used for arteriopathy and ulcer treatments. ${ }^{2,3}$ The results encouraged further studies, leading to the expansion of indications of new treatments. After the development of new technologies, the application was no longer topical and involved passing the $\mathrm{CO}_{2}$ to be 
infused directly into the subcutaneous tissue, ensuring faster and better results. Sequential studies described the effectiveness of the carboxytherapy treatment of localized adiposities; demonstrated measurable reductions in circumference regions of the abdomen, thigh, and/or knee; and showed histological evidence of the effect of gas leakage, showing its possible lipolytic effects. ${ }^{3,4}$ Ferreira et $\mathrm{al}^{5}$ described the increase in collagen remodeling induced by intradermal injections of $\mathrm{CO}_{2}$. In another study, Abramo et $\mathrm{al}^{6}$ showed that after the controlled infusion of $\mathrm{CO}_{2}$, vasodilation of the microcirculation skin was observed, accompanied by an increase of peripheral blood flow and an increase in skin temperature at the injection site (on average $3.48^{\circ} \mathrm{C}$ ). Cellulite affects, especially, the buttocks and thighs; its etiology is multifactorial and involves complex issues, and its treatment and evaluation require the use of new methodologies. $^{7-11}$ The lipolysis caused by carboxytherapy seems to be caused by temperature increase and local blood flow and have been demonstrated in previous studies; however, clinical studies are still required, with good analysis techniques that prioritize their effects on cellulite. ${ }^{2-6}$

This study aimed to verify the effectiveness of controlled infusion of $\mathrm{CO}_{2}$ in the treatment of cellulite in gluteal and posterior thigh bilaterally.

\section{Materials and methods}

This study began with a sample of 12 candidates and finished with ten of them with an average age of $29 \pm 6.1$ years and body mass index (BMI) of $25.5 \pm 3.3 \mathrm{~kg} / \mathrm{m}^{2}$. Inclusion criteria were healthy women, aged 20-35 years, BMI $<29.9 \mathrm{~kg} / \mathrm{m}^{2}$, with regular menstrual cycle, and presence of cellulite of gluteal and posterior thigh bilaterally as classified in degrees of severity II and III as in the current classification of cellulite ${ }^{12}$.

This study was approved by the Research Ethics Committee: União das Instituições de Serviço, Ensino e Pesquisa UNISEPE (CAAE: 02242112.9.0000.5490) and all subjects signed informed consent forms. The treatment was performed in the Clinical Laboratory of the Center for Education and Advanced Training CEFAI (Amparo, SP, Brazil). Volunteers were excluded if they were in aesthetic treatment; had had some kind of treatment in the gluteal region and thighs for a period leading up to 6 months before the start of this study; if they were pregnant or had had a recent pregnancy (<6 months); if they had cardiovascular problems, metabolic disorders, respiratory disorders, immunosuppression, kidney and liver failure, and skin lesions at the treatment site; or if they had diabetes mellitus. In assessing weight and height, the volunteers wore only underwear without shoes.

A classical mechanical stadiometer (model $110 \mathrm{CH}$; Welmy, SP, Brazil) was used. The BMI was evaluated by applying the formula BMI = weight in kilograms divided by the square of the height in meters $\left(\mathrm{kg} / \mathrm{m}^{2}\right) \cdot{ }^{13-15}$ Body fat percentage of each volunteer was measured with Biodynamics (Model 310E; TBW, SP, Brazil).

All volunteers received directions about the treatment steps and procedures to be performed. The treatment protocol consisted of eight sessions with an interval of 7 days. The evaluations were performed before the first treatment (baseline) and 7 days after the last treatment session. The total time between the baseline and the posttreatment reevaluation was $\sim 2.5$ months. After analysis of the area, ten points were selected for the infusion of $\mathrm{CO}_{2}$ (four in the gluteal area and six in the posterior thigh) as shown in Figure 1A. The treated areas were inspected and constantly monitored during all sessions. With a proper pen, points equidistant from each other were marked, $12 \mathrm{~cm}$ apart from each other, in places where the infiltration of $\mathrm{CO}_{2}$ was held. The antisepsis was performed with alcoholic chlorhexidine at $0.5 \%$. At each selected points, $80 \mathrm{~mL}$ of gas with a flow rate of $80 \mathrm{~mL} /$ min was infused. The needle was positioned at $45^{\circ}$ (inferior angle), and a subcutaneous puncture was made with a depth of $\sim 10 \mathrm{~mm}$ (Figure 1B).

After the application of the gas, the skin of the treated area was inspected. The equipment used in this study was ARES Carboxytherapy (IBRAMED, Indústria Brasileira de Equipamentos Médicos EIRELI, ANVISA 10360310032), and the medicinal $\mathrm{CO}_{2}$ used was from White Martins Gases Industriais Ltda (São Paulo, Brazil). Cellulite grades were determined by clinical inspection of the patient's skin, and standardized digital photographs with a digital camera (Canon EOS Rebel T3i, Canon USA Inc., Melville, NY, USA) were taken at baseline and 7 days after the proposed treatment. All patients were photographed in standing positions in three views: rear view, right side, and left side. The focus of the image was in the gluteal cleft with a focal length of $1 \mathrm{~m}$, and the muscles of the photographed areas were relaxed. Seven days after the last $\mathrm{CO}_{2}$ infiltration, new photographs were taken. The images were offered to independent evaluators together with the criteria for the verification aspect of the severity of cellulite. The stage of severity of cellulite according to what is generally accepted was used. Nürnberger and Müller describe different grades or stages of severity based on clinical presentation from 0 (zero) to III (three); $0=$ there is no alteration of the skin surface (visible without changes); $\mathrm{I}=$ the skin of the affected area is smooth while the subject is standing or lying, but the alterations to the skin surface can be seen by pinching the skin or with muscle contraction (visible changes with skin clamping or muscle contraction); $\mathrm{II}=$ the orange peel aspect of the skin or mattress appearance is evident when standing, without the use of any manipulation of the skin pinching or 
A
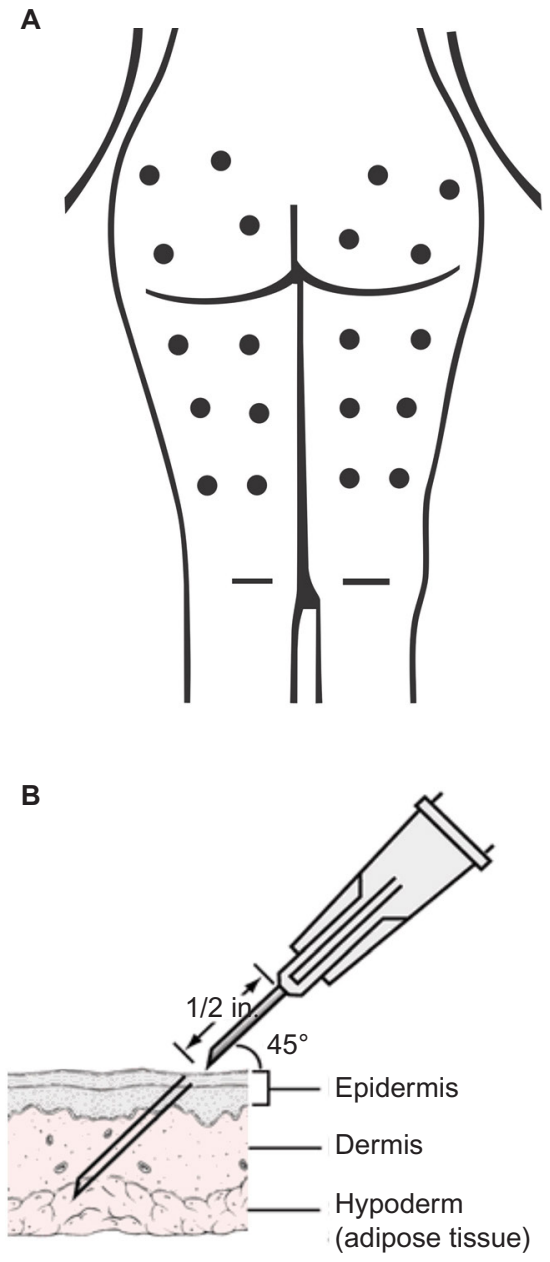

Figure I (A) Points of $\mathrm{CO}_{2}$ infusion; (B) position and angulation of needle placement for infusion, depth of $\sim 10 \mathrm{~mm}$ ( $30 \mathrm{G} \times 1 / 2$ inch size needle). muscle contraction (visible without manipulation); and III= the alterations described in grade or stage II, are present together with raised areas and nodules (visible changes associated with nodules). ${ }^{12}$ To minimize trends, reviews of the photographs were partially blind, ie, the evaluators received them in pairs without identifying which one represented the subjects before or after treatment. All the volunteers participating in the study underwent diagnostic ultrasound that was performed before and after the proposed treatment. All the volunteers underwent diagnostic ultrasound examination using a linear transducer (frequency 6-18 MHz) (MyLab ${ }^{\mathrm{TM}} 25$ Gold; Esaote, Italy), and VPan software (Esaote, Italy) was used for the construction of panoramic images. All panoramic images were taken in the standing position. The probe was slipped at a slow and regular speed in the distal/proximal direction along the areas. Panoramic images were analyzed qualitatively considering the hyperechoic areas. Bright echoes represent highly reflective structures (white $=$ dermis and fibrotic septa) and hypoechoic areas represent sparse echoes, reflection, or intermediate transmission (gray $=$ adipose tissue and skeletal muscle).

The paired Student's $t$-test was used for statistical analysis, with an alpha level of $5 \%(P<0.05)$ being considered significant.

\section{Results}

The volunteers were numbered 1-10, and evaluations were performed at baseline and 7 days after the last treatment session. Table 1 shows the anthropometric values before and after the infusion of $\mathrm{CO}_{2}$. There were no significant changes in

Table I Mean and standard deviation of the average of our patient population (age, body weight, BMl, and body fat percentage) at baseline and after treatment (7 days after the last carboxytherapy session).

\begin{tabular}{|c|c|c|c|c|c|c|c|}
\hline \multirow{2}{*}{$\begin{array}{l}\text { Volunteer } \\
N=10\end{array}$} & \multicolumn{3}{|c|}{ Weight (kg) } & \multicolumn{2}{|c|}{ BMI $\left(\mathbf{k g} / \mathrm{m}^{2}\right)$} & \multicolumn{2}{|c|}{ Body fat (\%) } \\
\hline & Age (years) & Baseline & After treatment & Baseline & After treatment & Baseline & After treatment \\
\hline I & 32 & 74.8 & 76.7 & 27.1 & 27.8 & 13.5 & 25.4 \\
\hline 2 & 31 & 63.5 & 64.0 & 23.8 & 23.9 & 13.7 & 20.2 \\
\hline 3 & 29 & 73.5 & 74.0 & 27.7 & 27.9 & 27.1 & 27.6 \\
\hline 4 & 36 & 85.5 & 87.5 & 29.6 & 30.3 & 30.8 & 23.5 \\
\hline 5 & 23 & 60.0 & 63.0 & 20.3 & 21.3 & 18.0 & 18.3 \\
\hline 6 & 21 & 64.5 & 63.0 & 23.1 & 22.6 & 21.9 & 18.7 \\
\hline 7 & 27 & 65.5 & 67.0 & 26.6 & 27.2 & 24.7 & 21.5 \\
\hline 8 & 33 & 62.5 & 65.5 & 25.0 & 26.2 & 15.4 & 17.4 \\
\hline 9 & 38 & 64.5 & 65.7 & 28.1 & 27.7 & 28.7 & 28.3 \\
\hline 10 & 20 & 56.0 & 53.8 & 21.2 & 20.5 & 17.1 & 16.0 \\
\hline Mean \pm SD & $29 \pm 5.9$ & $67.0 \pm 8.1$ & $68.0 \pm 9.3$ & $25.3 \pm 2.9$ & $25.5 \pm 3.3$ & $21.1 \pm 09$ & $21.7 \pm 4.3$ \\
\hline$P>0.05$ & & $P=0.10$ & & $P=0.20$ & & $P=0.73$ & \\
\hline
\end{tabular}

Notes: Classification weight by BMI: <18.5 (underweight), 18.5-24.9 (normal range), 25.0-29.9 (overweight), 30.0-34.9 (obesity class I), 35.0-39.9 (obesity class II), and $\geq 40.0$ (obesity class III). ${ }^{13-15}$

Abbreviations: BMI, body mass index; SD, standard deviation. 
anthropometric measures of weight $(P=0.10)$, BMI $(P=0.20)$, and body fat percentage $(P=0.73)$, at baseline and after the treatment.

Figure 2 shows a statistically significant reduction $(P=0.0025)$ in the aspect of cellulite; the images were handed over to three independent evaluators, and assessments of the photographs were partially blind according to generally accepted classification of cellulite.

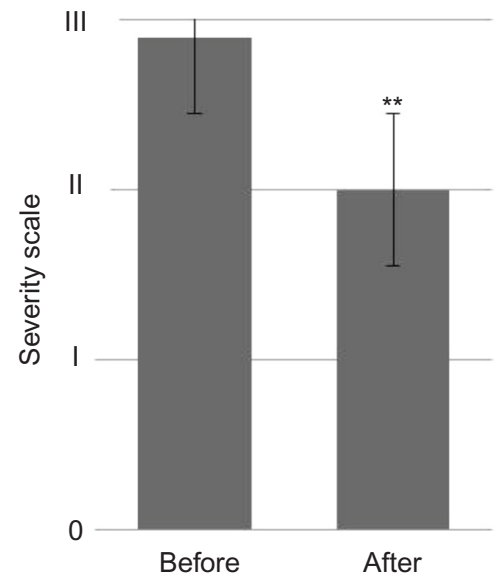

Figure 2 Cellulite degree evaluation according to generally accepted classification of cellulite, baseline (before) and 7 days after the last carboxytherapy session. Note: $* * P=0.0025$
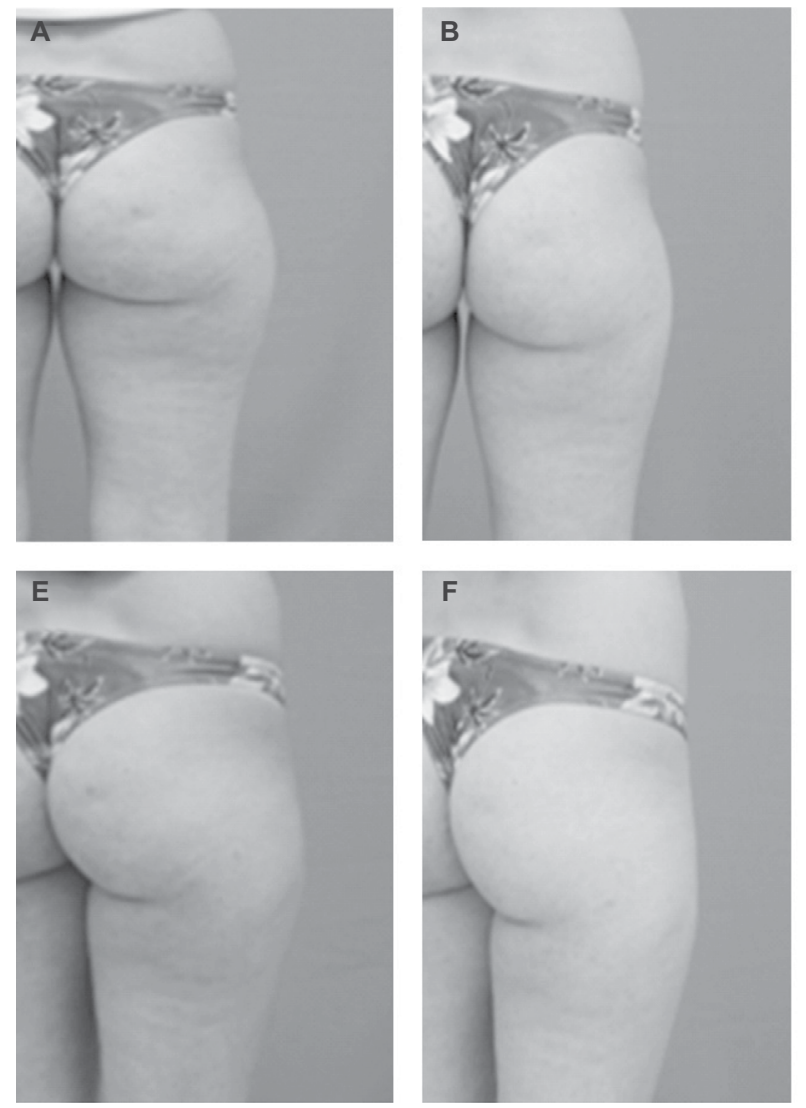

Figure 3 shows comparative photographic register of the aspect of cellulite at baseline and 7 days after the last carboxytherapy session.

In the panoramic image analysis performed by the ultrasound diagnosis, reduction of adipose tissue lodged between the skin and the muscles of the treated regions was verified, as seen in Figures 4 and 5. Qualitative analysis describes morphological improvement with respect to the subcutaneous tissue, fibrotic septa, and aspects of the dermis-related cellulite. The morphological improvement with respect to the subcutaneous tissue, fibrotic septa, and associated dermis aspect of the cellulite can also be seen.

\section{Discussion}

Cellulite is a multifactorial disorder and has a high prevalence in young adult women and despite no morbidity causes great dissatisfaction and negative influence on quality of life. ${ }^{1}$ The pathophysiology of cellulite was described as an aesthetically unpleasant disorder for most women after adolescence. It is a complex problem that includes changes involving the microcirculation, lymphatic system, extracellular matrix, and adipocytes. It affects certain body areas with more emphasis, such as thighs and buttocks. ${ }^{8}$ Studies also describe
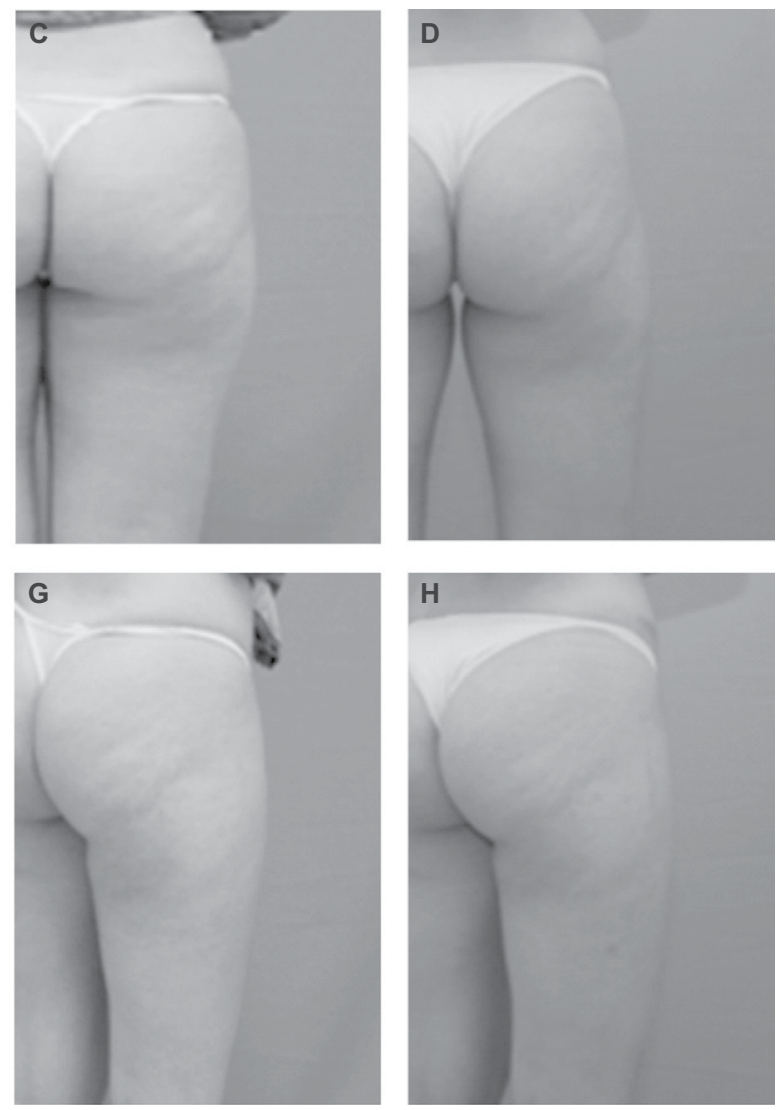

Figure 3 Comparative photographic register of the aspect of cellulite. Notes: (A, C) Rear view of gluteus and posterior right thigh at baseline; (B, D) rear view of right gluteus 7 days after the last carboxytherapy session; $(\mathbf{E}, \mathbf{G})$ right side view at baseline; and $(\mathbf{F}, \mathbf{H})$ rear view of the right gluteus after the last session of carboxytherapy. 

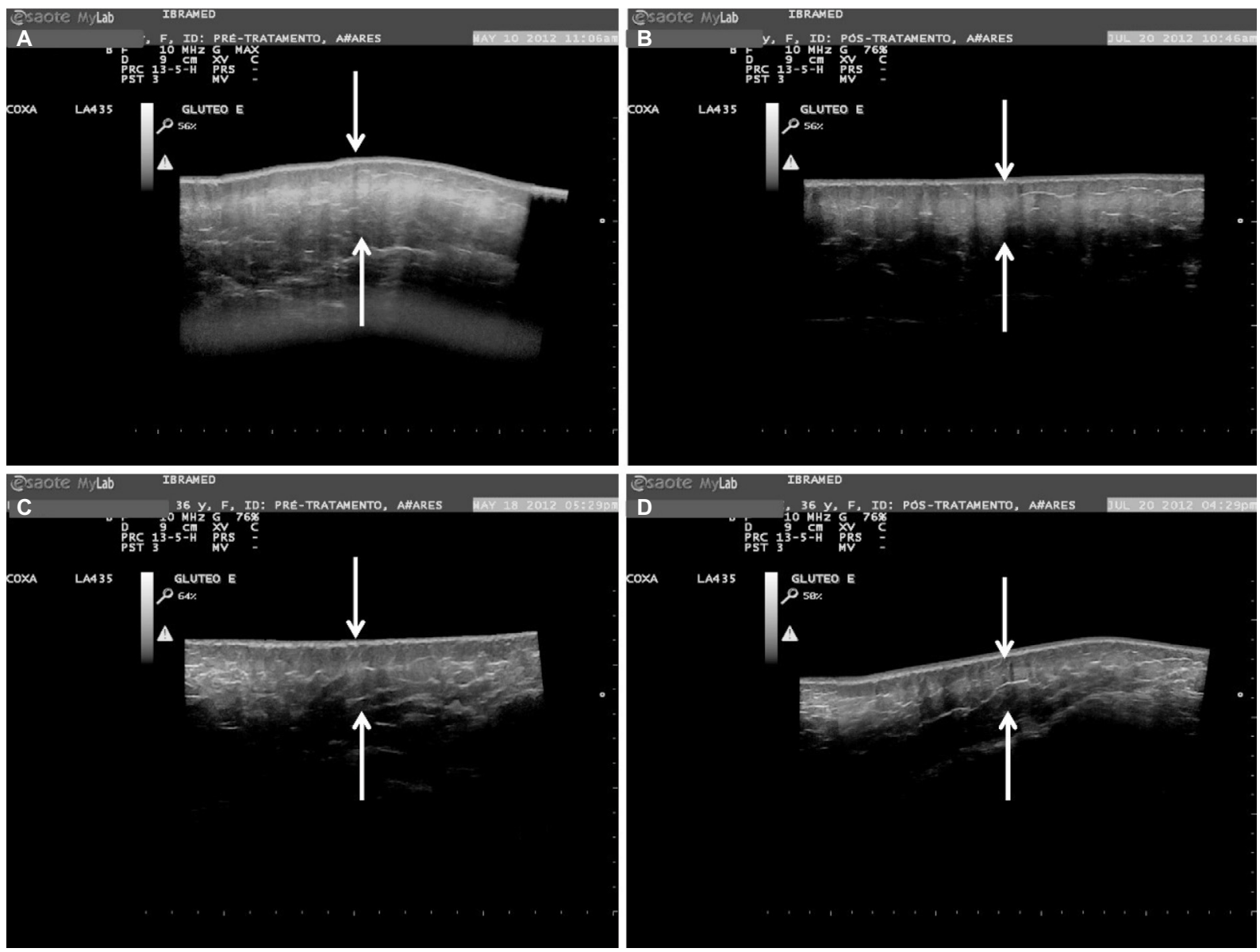

Figure 4 Comparative panoramic images of gluteal region.

Notes: (A, C) Before treatment with carboxytherapy; (B, D) 7 days after the last session. Note the hyperechoic areas: bright echoes, highly reflective structures (white = dermis and fibrotic septa) and hypoechoic areas: sparse echoes, reflection, or intermediate transmission (gray=adipose tissue and skeletal muscle). The arrows indicate the areas compared and the decrease of the thickness of the fibrotic septa after treatment.

the pathophysiology involving a hyperactivity of fibroblasts stimulated by estrogen, which increases the synthesis of glycosaminoglycans and collagen that increase interstitial osmotic pressure and water retention. A decrease in the capillary osmotic pressure in relation to the interstitial osmotic pressure generates edema and reduction in drainage with subsequent hyperpolymerization and formation of micronodules and fibrosclerotic collagen. Symptoms include edematous adiposity, incipient cellulite, or changes in the skin relief measured by the clinical severity. ${ }^{9,16,17}$ Adipose tissue can be divided anatomically into two layers by a layer of fibrous tissue called Camper's fascia. ${ }^{8}$ The areolar layer has fibrous septa arranged in a peculiar vertical architecture that connect the dermis filled by large globular adipocytes; below, the lamellar layer septa has more horizontal axis and the fat lobes are flattened. Adipocytes are specialized cells in the storage of fats. ${ }^{8-11,16-19}$ In 2004, it was demonstrated for the first time that the hypodermic infiltration of $\mathrm{CO}_{2}$ as an alternative measure to be associated with liposuction procedures was effective in treating localized adiposity or skin irregularities, resulting from the surgical procedure. Since then, the method has been used with increasing frequency in the treatment of different forms of lipodystrophies, as well as in aesthetic medicine. In this area, its main indications are in fighting cellulite in localized fat and sagging. ${ }^{20}$ Other studies show that controlled administration of medical $\mathrm{CO}_{2}$ into the subcutaneous tissue induces hypercapnia and decreases local $\mathrm{pH}$, which elicits a strong vasodilator response through the relaxation of the pre-arteriolar smooth muscle on the site. ${ }^{2,6,25}$ Histological features in the repair process showed the proliferation of newly formed small blood vessels and fibroblasts. ${ }^{21}$ The tissue stretching during infusion induces a subclinical inflammation, which triggers the repair and tissue regeneration processes that induce the activation of macrophages, fibroblasts, and endothelial cells that stimulate neovascularization and remodeling of the extracellular matrix. Among the diseases that may need carboxytherapy are peripheral artery disease and microangiopathy, psoriasis, varicose, and diabetic ulcers. This technique has also been frequently used for the treatment of cosmetic changes such 

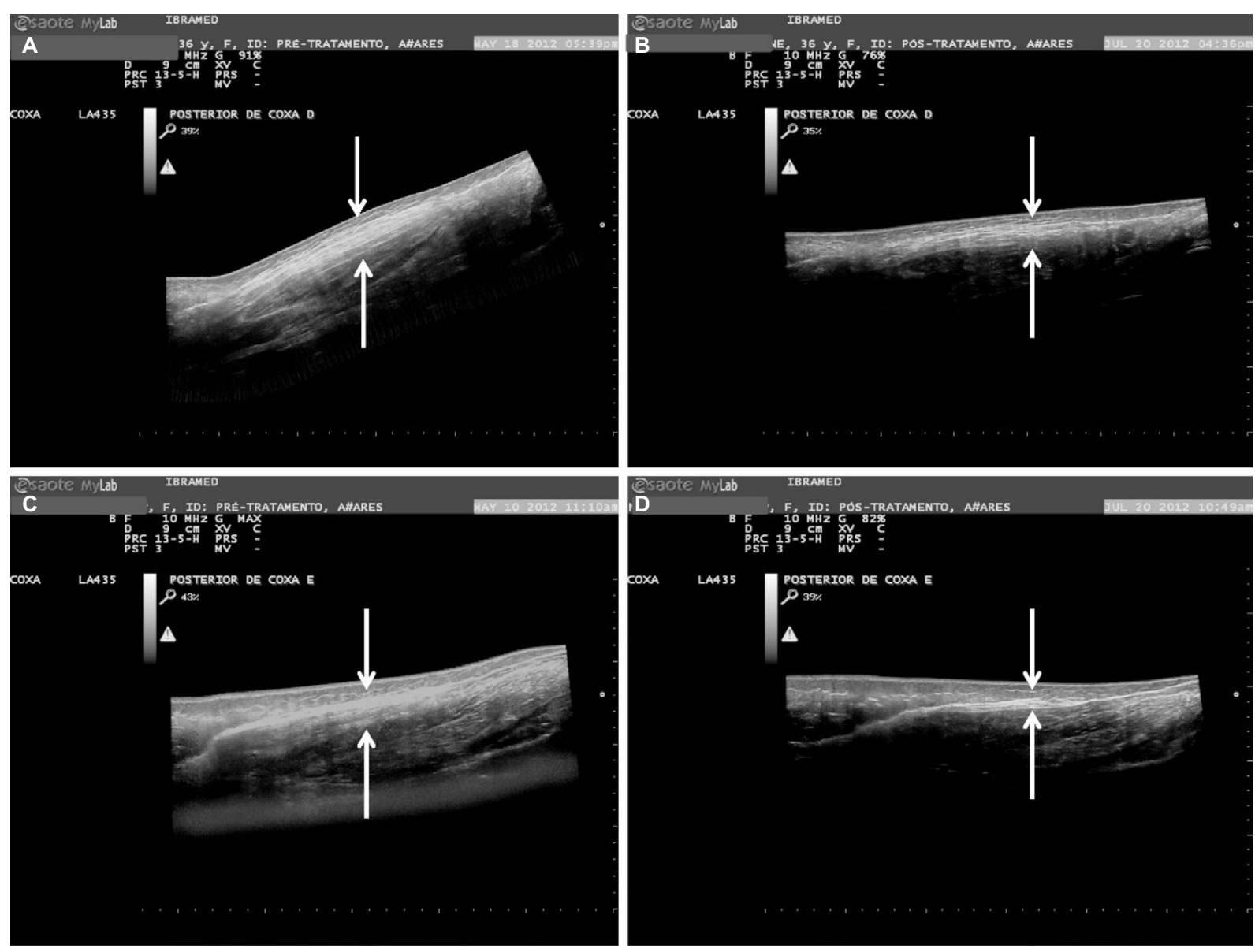

Figure 5 Comparative panoramic images of the posterior thigh.

Notes: $(\mathbf{A}, \mathbf{C})$ Before treatment with carboxytherapy; (B, D) 7 days after the last session. Note the hyperechoic areas: bright echoes, highly reflective structures (white = dermis and fibrotic septa) and hypoechoic areas: sparse echoes, reflection, or intermediate transmission (gray= adipose tissue and skeletal muscle). The arrows indicate the areas compared and the decrease of the thickness of the fibrotic septa after treatment.

as localized fat, cellulite, facial skin rejuvenation, alopecia, dark circles, and striae. ${ }^{2,4,20,22-26}$ In a study by Abramo et al, ${ }^{6}$ after the infusion of $\mathrm{CO}_{2}$, there was an average temperature increase of $3.48^{\circ} \mathrm{C}$ in the skin of the treated site. In addition, skin biopsies before and after treatment were evaluated by histology, and the authors observed that the diameter of the vessels increased by 3.24 times after treatment. Brandi et $\mathrm{al}^{4}$ described the effectiveness of carboxytherapy in the treatment of localized fat through measurable reductions in the circumference regions of the abdomen, thigh, and/or knee and showed histological findings of the effects of $\mathrm{CO}_{2}$ gas infiltration on the subcutaneous adipose tissue and their possible lipolytic effects. Corroborating these findings, a standardized study involved 15 volunteers subjected to carboxytherapy sessions on the anterior wall of the abdomen for 3 consecutive weeks. Two sessions per week at intervals of 2-3 days between each session were made, with infused fixed volume of $250 \mathrm{~mL}$ of $\mathrm{CO}_{2}$ per $100 \mathrm{~cm}^{2}$ of treated surface. Tissue biopsies were collected before and after treatment and analyzed by flow cytometry, which showed a significant reduction in the number and change in the morphology of the adipocytes in the treated area.

The objective of the study was to verify the effectiveness of carboxytherapy in the treatment of cellulite. During the treatment period, there were no significant changes in the body weight or BMI, as shown in Table 2. Photographic images captured in a standardized manner were analyzed by three independent evaluators and were partially blind. The visual inspection of photographic records of the areas treated with carboxytherapy showed statistically significant $(P=0.0025)$ changes regarding the aspect of improvement of the degree of severity, as shown in Figure 2. All volunteers showed improvement of skin appearance after carboxytherapy sessions, suggesting decreased tensile forces on the skin and possible redistribution of vertical forces (vector forces) in the septum (Figure 3). With regard to the safety of the carboxytherapy treatment, important studies report that the use of $\mathrm{CO}_{2}$ for contrast angiography attests to the safety of this gas and have shown that it is not likely to promote clots. $\mathrm{CO}_{2}$ can be used with intravascular bolus injections of up 
to $100 \mathrm{~mL}$ and continuous flows between 20 and $30 \mathrm{~mL} / \mathrm{s}$ without adverse reactions. ${ }^{27}$ In this study, 80 sessions with carboxytherapy were performed and no volunteer had any sort of significant adverse effects, but reported only mild transient discomfort, tolerable during treatment. One volunteer had two small bruises that resolved spontaneously, which suggests that carboxytherapy can be a safe technique. The treatment was tolerable for all the patients.

Noninvasive assessment techniques have been used to evaluate the cellulite and its posttreatment results, among which stand out the magnetic resonance imaging (MRI) and diagnostic ultrasound. Researchers, using microimages of the MRI, correlate the anatomy of the subcutaneous tissue to the typical changes in the cellulite at different degrees of severity; ${ }^{28}$ other researchers also used MRI to study the cellulite and its treatment with lymphatic drainage. ${ }^{29}$ However, the development of software that allows the use of panoramic images captured by diagnostic ultrasound is more inexpensive. Del Pino et $\mathrm{al}^{19}$ used this method to observe the results of the treatment of cellulite with nonablative radiofrequency. In this study, panoramic images taken by diagnostic ultrasound were used to evaluate the results of the treatment of cellulite with carboxytherapy. These images allowed the registration of large anatomical areas and the access of the subdermal structures, especially fibrotic regions of septa. All images were collected and evaluated, and the comparative differences can be clearly seen in Figures 4 and 5. The analysis of the structural aspect of cellulite allowed the observation of a significant improvement in the organization of fibrous lines observable by hyperechoic area (whitish structures of fibrotic septa) compared to pictures taken before treatment, also noting hypoechoic areas of adipose tissue. These results support the findings described by Lee ${ }^{25}$ in a compilation of clinical outcomes over 4 years (2004-2008) in 110 patients using carboxytherapy in the treatment of localized fat and cellulite; despite the methodological limitations of this study, the author concluded that carboxytherapy is a technique that demonstrates effectiveness for treating both localized fat and cellulite. The degrees of reduction of cellulite and possible reshaping of septa in this study likely occurred by the action of $\mathrm{CO}_{2}$ on the microcirculation and tissue perfusion, described in the subcutaneous tissue. Studies showed that local application of $\mathrm{CO}_{2}$ can promote improvement of peripheral circulation, increasing tissue perfusion and oxygen partial pressure by reflex vasodilation, and stimulate the neoangiogenesis. ${ }^{12}$ In the study, after the treatment of carboxytherapy, there was a significant reduction $(P=0.0025)$ of the cellulite from degree III to degree II, and this improvement showed correlation with the improvement in the organization of fibrous lines and the disposal of adipose tissue lines of treated regions observed through the panoramic ultrasound image diagnosis. Another factor that may contribute to the effectiveness of carboxytherapy in the treatment of cellulite is the decrease in the density and shape of adipocytes in the treated area as demonstrated in the study by Costa et al, ${ }^{24}$ since the accumulation of localized fat could contribute to increased local tissue compression, favoring the traction of fibrotic beams and herniation of adipocytes in the dermis causing the appearance of the orange peel skin depressions, a characteristic feature of cellulite disorder.

\section{Conclusion}

This pilot study showed that carboxytherapy may be used to improve the degree of severity of cellulite in the subcutaneous tissue at the buttocks and posterior thighs of healthy women. Further studies with a larger number of patients will be needed to more fully characterize the full clinical potential of carboxytherapy and its mechanism of action.

\section{Acknowledgment}

The authors thank Ms Alexandra Paioli for English language and grammatical technical support.

\section{Disclosure}

Renata Michelini Guidi and Estela Sant'Ana are researchers at IBRAMED Indústria Brasileira de Equipamentos Médicos EIRELI. The other authors report no conflicts of interest in this work.

\section{References}

1. Schonvvetter B, Soares JLM, Bagatin E. Longitudinal evaluation of manual lymphatic drainage for the treatment of gynoid lipodystrophy. An Bras Dermatol. 2014;89(5):712-718.

2. Varlaro V, Manzo G, Mugnaini F, et al. Carboxytherapy: effects on microcirculation and its use in the treatment of severe lymphedema. Blood. 2007;8:1-13.

3. Corassa JM, Pereira FLC, Penha MR, Corassa MP. Uso da carboxiterapia no tratament o de distúrbios vasculares : resultados preliminares [Use of carboxitherapy in the treatment of vascular disorders: preliminary results]. Revista de Angiologia e Cirurgia Vascular. 2006; 8. Portuguese.

4. Brandi C, D'Aniello C, Grimaldi L, et al. Carbon dioxide therapy in the treatment of localized adiposities: clinical study and histopathological correlations. Aesthetic Plast Surg. 2001;25(3):170-174.

5. Ferreira JCT, Haddad A, Tavares SAN. Increase in collagen turnover induced by intradermal injection of carbon dioxide in rats. $J$ Drugs Dermatol. 2008;7(3):201-206.

6. Abramo AC, Oliveira TT, Ledo-Silva MC, Oliveira EL. Elevação da temperatura cutânea após a infusão controlada de dióxido de carbono [Increase of the skin temperature after infusion-controlled carbon dioxide]. Rev Bras Cir Plástica. 2009;24(3):257-261. Portuguese.

7. Sant'Ana EMC, Marqueti RDC, Leite VL. Revisão fibro edema gelóide (celulite): fisiopalogia e tratamento com endermologia [Gynoid lipodistrophy: pathophysiology and treatment with endermologie. A review]. Fisioterapia Especialidades. 2007;1:30-35. Portuguese.

8. Rawlings AV. Cellulite and its treatment. Int J Cosmet Sci. 2006;28(3): 175-190. 
9. Rossi ABR, Vergnanini AL. Cellulite: a review. J Eur Acad Dermatol Venereol. 2000;14(4):251-262.

10. Querleux B, Cornillon C, Jolivet O, Bittoun J. Anatomy and physiology of subcutaneous adipose tissue by in vivo magnetic resonance imaging and spectroscopy: relationships with sex and presence of cellulite. Skin Res Technol. 2002;8(2):118-124.

11. Rosenbaum M, Prieto V, Hellmer J, et al. An exploratory investigation of the morphology and biochemistry of cellulite. Plast Reconstr Surg. 1998;101(7):1934-1939.

12. Hexsel D, Mazzuco R. Cellulite. In: Tosti A, Hexsel, D, editors. Update in Cosmetic Dermatology. Mumbai: Springer-Verlag Berlin Heidelberg; 2013:21-32.

13. Seidell JC, Flegal KM. Assessing obesity: classification and epidemiology. British Medical Bulletin. 1997;53(2):238-252.

14. Anuurad E, Shiwaku K, Nogi A, et al. The new BMI criteria for Asians by the regional office for the Western Pacific Region of WHO are suitable for screening of overweight to prevent metabolic syndrome in elder Japanese workers. J Occup Health. 2003;45:335-343.

15. James PT, Leach R, Shayeghi M. The worldwide obesity epidemic. Obesity Research. 2001;9(4):228S-233S.

16. Terranova F, Berardesca E, Maibach H. Cellulite: nature and aetiopathogenesis. Int J Cosmet Sci. 2006;28(3):157-167.

17. Khan MH, Victor F, Rao B, Sadick NS. Treatment of cellulite. Part I. Pathophysiology. J Am Acad Dermatol. 2010;62(3):361-370.

18. De Lorenzi DRS, Basso E, Fagundes PDO, Saciloto B. Prevalência de sobrepeso e obesidade no climatério. Rev Bras Ginecol e Obs. 2005;27(8): 479-484.

19. Del Pino ME, Rosado RH, Azuela A, et al. Effect of controlled volumetric tissue heating with radiofrequency on cellulite and the subcutaneous tissue of the buttocks and thighs. J Drugs Dermatol. 2006;5(8): 714-722.

20. Paolo F, Nefer F, Paola P, Nicolò S. Periorbital area rejuvenation using carbon dioxide therapy. J Cosmet Dermatol. 2012;11(3):223-228.
21. Maia-Figueiró TL, Odashiro AN, Menezes GP, et al. Semi-quantitative histological analysis of the effect of intense pulsed light (IPL) and carbon dioxide $\left(\mathrm{CO}_{2}\right)$ intradermic injection on fibroblast and collagen proliferation in the skin of Wistar rats. J Cosmet Dermatol Sci Appl. 2012;02(03):164-173.

22. Irie H, Tatsumi T, Takamiya M, et al. Carbon dioxide-rich water bathing enhances collateral blood flow in ischemic hindlimb via mobilization of endothelial progenitor cells and activation of NO-cGMP system. Circulation. 2005;111(12):1523-1529.

23. Piazzolla LP, Louzada LL, Scoralick FM, Martins ME, de Sousa JB. Preliminary experience with carbon dioxide therapy in the treatment of pressure ulcers in a bedridden elderly patient. $J$ Am Geriatr Soc. 2012;60(2):378-379.

24. Costa CS, Otoch JP, Seelaender MCL, et al. Avaliação citométrica dos adipócitos localizados no tecido subcutâneo da parede anterior do abdome após infiltração percutânea de $\mathrm{CO}_{2}$ [Cytometric evaluation of abdominal subcutaneous adipocytes after percutaneous $\mathrm{CO}_{2}$ infiltration]. Rev Col Bras Cir. 2011;38(1):15-23. Portuguese.

25. Lee GSK. Carbon dioxide therapy in the treatment of cellulite: an audit of clinical practice. Aesthetic Plast Surg. 2010;34(2):239-243.

26. Brandi C, Grimaldi L, Nisi G, et al. The role of carbon dioxide therapy in the treatment of chronic wounds. In Vivo. 2010;24(2):223-226.

27. Simão JR, Guillaumon AT. Estudo angiográfico de fístula arteriovenosa utilizando gás carbônico como meio de contrante [Arteriovenous fistula angiography using carbon dioxide as contrast medium]. Radiol Bras. 2004;37(6):397-403. Portuguese.

28. Mirrashed F, Sharp JC, Krause V, Morgan J, Tomanek B. Pilot study of dermal and subcutaneous fat structures by MRI in individuals who differ gender, BMI, and cellulite grading. Ski Res Technol. 2004;10(3): 161-168.

29. Meyer PF, Martins NM, Martins FM, Monteiro RA, de Mendonça KMPP. Effects of lymphatic drainage on cellulitis assessed by magnetic resonance. Brazilian Arch Biol Technol. 2008;51(Special issue):221-224.
Clinical, Cosmetic and Investigational Dermatology

\section{Publish your work in this journal}

Clinical, Cosmetic and Investigational Dermatology is an international, peer-reviewed, open access, online journal that focuses on the latest clinical and experimental research in all aspects of skin disease and cosmetic interventions. This journal is included on PubMed. The manuscript management system is completely online

\section{Dovepress}

and includes a very quick and fair peer-review system, which is all easy to use. Visit http://www.dovepress.com/testimonials.php to read real quotes from published authors 